\title{
PRESENCIA DEL TEATRO CALDERONIANO \\ EN LA ESCENA GADITANA (1803-1813)
}

\author{
Marieta Cantos Casenave \\ Departamento de Filología \\ Universidad de Cádiz \\ Calle Ancha, 16 \\ 11001 Cádiz. España \\ marieta.cantos@uca.es
}

El repaso que pretendo realizar por la cartelera gaditana a lo largo de más de una década tiene el interés de dar cuenta del contexto escénico en que se produce la famosa «querella calderoniana». Según Llorens (1989), en Cádiz, hacia 1818 no se programaba teatro del Siglo de Oro, lo que obligó a Juan Nicolás Böhl a preparar una representación ad hoc de $A$ secreto agravio, secreta venganza, con motivo de la llegada a Cádiz de «dos sabios naturalistas alemanes», a los que interesaba conocer dicho teatro, que tampoco - asegura - habían podido ver representado en Madrid. Llorens afirma, además, que en esas fechas solo se representó El desdén con el desdén y una refundición del Burlador de Sevilla. Creo que para contrastar las afirmaciones de Llorens conviene primero analizar qué teatro se representaba en Cádiz antes de que se desarrollara la «querella», pues como ya he puesto de manifiesto en otra ocasión la preocupación que muestran Juan Nicolás y su mujer Frasquita Larrea por la literatura del Siglo de Oro en general, y por la vigencia del teatro de Calderón en particular, es anterior. Ya en 1806 Juan Nicolás y Frasquita 
se planteaban estas cuestiones ${ }^{1}$ y esta última en 1810 vuelve a releer a los clásicos españoles, particularmente a Calderón, al tiempo que reivindica a Lope y a otros escritores que consideraban representantes del genio español.

Voy a ocuparme, pues, de unos años decisivos, los que van de 1803 a 1813, en los que, si al principio continúan las prácticas escénicas habituales en los últimos años del siglo XVIII, desde 1807 se percibirán unos cambios en la vida política y cultural, a raíz de la aparición de un personaje fundamental en el contexto europeo, Napoleón, cuya intención de engañar a su supuesto aliado, la monarquía hispánica, al invadir la península ibérica, supondrá el inicio de una guerra total que afectará a todos los ámbitos. Esto condicionará, lógicamente, también la dramática, incluso en mayor medida, por sus posibilidades de convertirse en instrumento de propaganda patriótico y político. En este sentido se evidencia la aparición de un repertorio dramático, ligado a las «circunstancias del día» - como lo denomina la prensa del momento-, que alternará en el gusto con las "comedias antiguas» del teatro del Siglo de Oro, traducciones y «comedias nuevas» o arregladas o refundidas ${ }^{2}$. Así pues, en el repaso a la cartelera necesariamente se habrá de insistir en examinar permanencias y cambios en dos etapas diferentes: la de 1803 hasta mayo de 1808, puesto que no hay teatro en el mes de junio - -seguramente la incertidumbre provocada por los sucesos de mayo explica que el teatro no retome las representaciones hasta el 22 del mes siguiente- $\mathrm{y}$ desde finales de julio ${ }^{3}$ a diciembre de 1813 , año en el que, además de ser derrotados los franceses, Cádiz deja de ser la capital del reino y de ser la sede del congreso de los diputados que acababan de publicar la Constitución de 1812.

En esta segunda etapa se producen también una radicalización en los debates de las Cortes, concretamente en torno al decreto de li-

${ }^{1}$ Cantos, 2002

${ }^{2}$ Generalmente las comedias arregladas o refundiciones suelen tener cinco actos cuando se trata de asunto trágico. Por otra parte, aunque a veces resulta ambiguo, hay que tratar de distinguir entre "comedia nueva», es decir ajustada al canon neoclásico, frente a la etiqueta de "comedia antigua», que se asigna explícitamente a algunas de Calderón y «comedia nueva en este teatro», que solo llama la atención sobre la novedad de su aparición en cartel o a que se represente después de varios años seguidos sin hacerlo.

${ }^{3}$ En los años que me ocupan, la representación teatral se mantiene durante los días de verano. 
bertad de imprenta de 10 de noviembre de 1810, modificado en el decreto de 1813 y sobre la abolición en este último año del tribunal de la Inquisición. No es casual que en estos mismos años se genere una tremenda controversia sobre el papel del teatro como escuela patriótica y política a raíz del intento de reabrir el coliseo Principal que, cerrado por la cuaresma, no inició la nueva temporada a causa del peligro que suponía la proximidad del ejército francés ${ }^{4}$. La última obra que se representó en 1810 fue la obra patriótica de Diego del Castillo, Origen del patriotismo del héroe de Somosierra o sea el Empecinado el 31 de enero, mientras se recurrió a una obra clásica, El desdén con el desdén, para la reapertura el 20 de noviembre de 1811, después de una campaña iniciada por Mexía Lequerica, sostenida por el Semanario Patriótico de Manuel José Quintana y con la resistencia de reaccionarios como M. ${ }^{a}$ Manuela López de Ulloa, que consideraba el teatro un espacio propicio para el contagio de todo tipo de pasiones sentimentales y políticas ${ }^{5}$.

Analizar la vigencia y el sentido de la representación del teatro calderoniano en estas circunstancias será uno de los objetivos de este trabajo, en el que señalaré además cuáles son los autores y las obras más representadas, para así contrastar la tesis de Llorens, que viene a superponerse a la mantenida por otros autores. Como punto de partida he tenido en cuenta el trabajo de Ann L. Mackenzie 6 , pero considero que, aun cuando en opinión de esta investigadora, si bien Luis Vélez de Guevara y Belmonte Bermúdez escribieran obras en colaboración con Calderón y su escuela, no puede considerárseles sino seguidores de la fórmula de Lope, para los años de referencia de este estudio no es esta una cuestión fundamental, pues Böhl de Faber y Frasquita Larrea, entre otros, al tiempo que reivindican la genialidad de Calderón, no dejan de alabar a Lope y a su escuela. En este sentido, la nómina final se compone, además del propio Calderón, de Rojas Zorrilla y Antonio Coello — con los que Calderón escribió en colaboración durante los años 30- y de otros jóvenes como Belmonte, Montalbán, Zárate, Hoz y Mota o incluso Luis Vélez de Guevara, seguidor de Lope, pero también colaborador de Calderón y su escuela, como acabo de señalar ${ }^{7}$. Asimismo se inclui-

${ }^{4}$ Aunque Larraz (1977) señaló el cierre del teatro a principio de 1810, es Ramos Santana (2008) quien explica todas las circunstancias que acompañan a este proceso.

${ }^{5}$ Cantos, 2013.

${ }^{6}$ Mackenzie, 1993.

${ }^{7}$ Mackenzie, 1993, p. 38. 
rán otros seguidores como Cubillo, Monroy y Silva, Bances Candamo, Diamante, Matos Fragoso o Pedro Lanini, que Mackenzie considera de segundo o tercer «rango» ${ }^{8}$.

Finalmente, respecto de Lope y sus seguidores, incluiré en este estudio al propio Lope, a Tirso de Molina, a los colaboradores de Calderón ya citados Belmonte Bermúdez y Vélez de Guevara, a Mira de Amescua, Guillén de Castro y Juan Pérez de Montalbán, pues otros no se representan durante estos años.

Para empezar, conviene recordar las palabras de Caldera cuando señalaba en su estudio "Calderón desfigurado»" que el repertorio calderoniano representado en Madrid se limitaba a las obras que gozaban del mayor favor popular, es decir, comedias de enredo, como El astrólogo fingido, La dama duende, Casa con dos puertas, frente a los dramas filosóficos o de temática más compleja como La vida es sueño, El alcalde de Zalamea, o El médico de su honra. En la misma línea, Mercedes Romero asegura que las más exitosas en el periodo de «1800 a 1808 fueron El garrote más bien dado» ${ }^{10}$, de Calderón, La dama melindrosa, de Lope en refundición de Trigueros y Si no vieran las mujeres y Los Tellos de Meneses, de Tirso.

Limitándome ya a la escena gaditana creo que podré demostrar que, aunque en buena medida el repertorio coincide con el madrileño respecto de la representación de traducciones y comedias nuevas, existe una relativa independencia en lo que se refiere al resto. La primera cifra que quiero aportar es la de un total de 23 obras de Calderón — antiguas o refundidas, a veces es dificil saberlo- que alcanzaron un total de 104 representaciones. Entre las grandes ausencias cabe mencionar La niña de Gómez Arias, sobre el tema del burlador encarnado en un soldado rufián que dice buscar en cada enamorada la perfección y El alcalde de Zalamea,

${ }^{8}$ Mackenzie, 1993, p. x. En otras ocasiones la misma investigadora asegura que Lanini, junto con Hoz y Mota, Zamora y Cañizares «seguían imitando al maestro con razonable aptitud y éxito durante los últimos años del xvir y primeros decenios del siglo XVIII" (Mackenzie, 1993, p. 151). Cabe recordar que tanto Lanini como Cañizares son responsables de la aprobación para su representación de obras como El galán fantasma en 1704 y 1707, como aparece en la nota manuscrita de la digitalización realizada por la Biblioteca Virtual Miguel de Cervantes. Por otra parte, dejo fuera a Juan Bautista Diamante, del que no he logrado hallar ninguna obra representada en estos años en Cádiz.

${ }^{9}$ Caldera, 1983.

${ }^{10}$ Romero, 2008, p. 189. 
que sin embargo, como he apuntado antes, fue uno de los mayores éxitos en la escena madrileña y lo será en Cádiz en fechas posteriores ${ }^{11}$.

La primera obra de Calderón que sube a la escena en estos años es Las armas de la hermosura el 7 de enero de 1803 y se repite prácticamente todos los años hasta el 21 de septiembre de 1807, luego desaparece del cartel hasta que vuelva a reaparecer más de diez años después el 23 de diciembre de 1812. El 23 de enero hay una función doble, en que se pone en escena Amar después de la muerte o El Tuzaní de las Alpujarras, también de Calderón, seguida de tonadilla y sainete, a las 4 y luego a las 7 y media. El buen labrador, obra de Comella, con tonadilla, sainete y boleras. El Tuzaní subirá de nuevo a las tablas el 20 de octubre de ese mismo año de 1803 y luego dos días seguidos de 1806 (9 y 10 de febrero) y otros dos en 1807 (14-15 de noviembre); y de nuevo el 25 de junio y el 12 de diciembre de 1808 para desaparecer desde esa fecha.

La siguiente obra de Calderón en ser representada es Para vencer amor, querer vencerle, el 16 de abril de 1803 y lo hará en 12 ocasiones más hasta 1807; comenzada la Guerra de la Independencia, subirá a las tablas cuatro veces más (20 de enero de 1810; 28 de enero de 1812; 7 de diciembre de 1812; 14 de junio de 1813) lo que suma un total de 16 representaciones, convirtiéndose en la obra de mayor éxito de este autor.

Aunque no fue la que contó con mayor apoyo del público, frente a lo que cabía esperar de las palabras de Llorens, $A$ secreto agravio secreta venganza sube a la escena en dos días del temprano 1803 (22 de julio y 10 de octubre) y aún será representada a primeros de 1813, el 13 de febrero; no obstante, habrá que ver qué ocurre en los años siguientes. También el 12 de septiembre de 1803 se representa una obra calderoniana fundamental: El médico de su honra, aunque no vuelve a subir a la escena en el periodo que me ocupa.

Cabe decir, sin embargo, que la obra más representada no es de Calderón, sino la refundición de una obra de Lope, Sancho Ortiz de las Roelas, adaptada al gusto del día por Cándido M. ${ }^{a}$ Trigueros, que lo es hasta en 23 ocasiones y, por tanto, supera con creces a la más represen-

${ }^{11}$ Agradezco a María Rodríguez Gutiérrez que me haya permitido conocer un adelanto de su tesis, de la que presentó algunos avances en el Congreso celebrado en Cádiz en octubre de 2014. María Rodríguez señala que El alcalde de Zalamea es la obra más representada, en una docena de ocasiones, con indicación explícita, ya en el sexenio absolutista, de ser obra refundida bajo el título de El garrote más bien dado y Alcalde de Zalamea; La niña de Gómez Arias solo subirá a las tablas en el Trienio. 
tada de Calderón que es Para vencer amor, querer vencerle. No obstante, conviene recordar que el número de obras de Calderón llevadas a la escena es superior.

Una representación única tuvo Duelos de amor y lealtad, tragedia «historial» según la clasificación de Bances Candamo, sobre la conjuración de los persas, en la que el motivo del poder político se une con el de la injusticia y la venganza — como Amar después de la muerte, que subió en ocho ocasiones, y Un castigo en tres venganzas, que alcanzó tres-, El médico de su honra, drama de honor o de uxoricidio ${ }^{12}$, que tuvo menos fortuna que $A$ secreto agravio, secreta venganza, con tres representaciones, donde se desarrolla el mismo motivo, aunque bien es cierto que tampoco esta obra tuvo notable favor del público; así como La vida es sueño, representada igualmente en una ocasión, pero ya al final de este periodo, el 8 de junio de 1813, lo que anticipa el mayor éxito que tendría bajo el reinado de Fernando VII, como estudia María Rodríguez Gutiérrez en la tesis que está redactando.

Aunque fueron representadas al menos en dos ocasiones, no lograron gran éxito Afectos de odio y amor, una comedia palatina cuya protagonista se identifica con la reina Cristina de Suecia, reina y mujer de gran educación que despertó una gran admiración y curiosidad entre todos sus coetáneos y en particular se mostró gran defensora de la valía de la mujer; Apeles y Campaspe o sea Darlo todo y no dar nada, que cuestiona el poder de un tirano como Alejandro para regalar lo que no tiene, el alma de Campaspe, una mujer fuerte, que es a un tiempo encarnación del libre albedrío; El galán fantasma, comedia de enredo sobre el amor y la muerte. A estas se añaden, Cada uno para sí, una comedia cómica, de capa y espada, donde los lazos de la amistad se obvian a fin de tratar de alcanzar cada uno el objeto amoroso; El cisma de Inglaterra, sobre la coyuntura dramática surgida en torno al personaje histórico de Ana Bolena y $\mathrm{La}$ banda y la flor, otra comedia palatina de amor y celos.

En tres ocasiones subieron a las tablas $A$ secreto agravio, secreta venganza y Un castigo en tres venganzas ${ }^{13}$ donde justicia y venganza ${ }^{14}$ coinciden, como en las ya mencionadas La niña de Gómez Arias, y el Alcalde de

12 Johnston, 1998, pp. 235-249.

${ }^{13}$ Dos antes de la Guerra de Independencia, 22.07.1803 y 10.10 .1803 y otra después, el 13.02.1813. Por razones de espacio, a partir de aquí doy las referencias abreviadas de las fechas de representación.

${ }^{14}$ Bigelow, 1983. 
Zalamea. El mismo número de veces suben a escena No siempre lo peor es cierto, en la que Leonor, con la esperanza de que el tiempo descubra la verdad, soporta las dudas de Carlos, el caballero que cree estar seguro de su infidelidad y Mañanas de abril, y mayo ${ }^{15}$; lo mismo que El astrólogo fingido que, en la refundición de Dionisio Solís, obtuvo uno de los mayores éxitos en ciudades como Madrid ${ }^{16}$, pero en Cádiz solo fue representada antes de la Guerra de Independencia; en todo caso, merece la pena indicar que, cuando se anuncia los días 21 y 22 de octubre de 1806 , se advierte con respecto a la obra que será representada una «comedia en tres actos» de «nuestro célebre D. Pedro Calderón de la Barca, jamás representada en este teatro», lo que parece apuntar a que en el caso gaditano no se trata de la refundición de Solís. Esta división tripartita se mantiene cuando se representa el 22 de diciembre del mismo año, aunque ya no se mencione a Calderón. Mediano favor del público gozaron Bien vengas mal si vienes solo ${ }^{17}$ (6 representaciones), La gran Cenobia (6) ${ }^{18}$, El mayor monstruo los celos, y Tetrarca de Jerusalén (5) y El secreto a voces (5).

En el extremo contrario, las historias que en más ocasiones subieron a las tablas son Las armas de la hermosura (10), una comedia "historial» con Coriolano como protagonista, que combina el poder político con el motivo de la injusticia, lo mismo que la ya mencionada Duelos de amor y lealtad; también el amor trágico de Amar después de la muerte o El Tuzaní de las Alpujarras (11), situada durante la represión de los moriscos por Felipe II. La diferencia entre ellas es el desenlace feliz logrado gracias al amor y a la virtud, en el marco de dos "fiestas palaciegas»" ${ }^{19}$, a diferencia del desenlace infausto de El Tuzaní. El mismo éxito disfrutó La dama duende (11), que, por otra parte, se anuncia en ocasiones como "comedia original española».

${ }^{15}$ Una antes de la Guerra de Independencia, 12/02/1808 y otras dos el 16/12/1812 y el 10/01/1813.

${ }^{16}$ Cotarelo, 1902, p. 21.

${ }^{17}$ El 17 de noviembre de 1804, para retomar la vida teatral después de las epidemias padecidas por la ciudad, se elige la «graciosa comedia de nuestro poeta Pedro Calderón de la Barca», Bien vengas mal si vienes solo, y se mantiene al día siguiente. Por razones de espacio, a partir de aquí incluyo entre paréntesis el número de representaciones de cada una de estas obras.

${ }^{18}$ Se representó por primera vez el 14 de diciembre de 1803, «en el día de la princesa de Asturias».

${ }^{19}$ Novo, 2002, p. 290. 
Las que mejor acogida tuvieron fueron Casa con dos puertas (12), cuyo enredo amoroso y juego cómico explica sobradamente su éxito y, muy por encima de ella, Para vencer amor, querer vencerle $(16)^{20}$.

Para recapitular, cabe señalar que la media de representaciones por obra se sitúa en el caso de Calderón en torno a las cuatro ocasiones, aunque hay que tener en cuenta que el de 1803 fue un año en el que diez obras de Calderón subieron a las tablas, si bien algunas como $\mathrm{El}$ cisma de Inglaterra y El médico de su honra no volvieron a ser representadas en años posteriores. A este respecto, cabe añadir que la producción de Calderón está más presente en el periodo anterior al comienzo de la Guerra de la Independencia, con un total de 90, mientras que su número desciende a 32 desde julio 1808;pero conviene tener en cuenta que, a pesar de lo dicho, en los años de 1812-1813 se mantienen en cartel ocho títulos, de los que solo cuatro - La dama duende, Para vencer amor, querer vencerle y Casa con dos puertas, así como La lavandera de Nápoles, escrita en colaboración con Rojas Zorrilla y Pérez de Montalbánpermanecen durante este bienio.

Retomando el hilo cronológico, cabe señalar que hasta finales de 1806 no se representa El astrólogo fingido, que lo hará el 21 y 22 de octubre. Por fin dos años después, en enero de 1807, el día 29 se pone en escena El galán fantasma, mientras el 31 subirá a las tablas La dama duende ${ }^{21}$. El 3 de abril Casa con dos puertas $^{22}$ y el 11 La dama duende ${ }^{23}$. La más hidalga hermosura, el 8 de octubre y Un castigo en tres venganzas, el 22.

En el año de 1808 se representa Mañanas de abril y mayo el 12 de febrero de $1808^{24}$; El secreto a voces, 30 de abril y el 10 de octubre; Amar después de la muerte, 25 de mayo y el 12 de diciembre, así como La banda y la flor ${ }^{25}, 26$ de junio. Los años de 1809 y 1810 son los más flojos: solo se representa No siempre lo peor es cierto, el 5 de julio de 1809 y Para vencer amor, querer vencerle el 20 de enero del año siguiente. Ninguna obra de Calderón se representa durante los dos meses que se abre el teatro en 1811. Además de las mencionadas, en 1812 suben a las tablas Bien vengas

${ }^{20}$ De esta comedia, como de otras del autor, existe una relación impresa en 1758 por Manuel Nicolás Vázquez.

${ }^{21}$ Volverá a las tablas el 2 de enero de 1812.

${ }^{22} 24$ de septiembre de y el 22 de abril de 1808 Y el 19 de noviembre de 1808.30 marzo 1812, 14 de junio, 26 de abril de 1813.

${ }^{23} 7$ de mayo 1812 y 18 de febrero, y 7 de junio de 1813.

${ }^{24}$ Con el reclamo de su autor «Don Pedro Calderón de la Barca».

${ }^{25}$ Y el 9 de noviembre de 1808. 
mal si vienes solo, Mañanas de abril y mayo, El mayor monstruo los celos y Tetrarca de Jerusalén, y El secreto a voces. En 1813 se recupera $A$ secreto agravio, secreta venganza, De un castigo tres venganzas, Mañanas de abril, y mayo y sube por primera vez, La vida es sueño. Algunos títulos más se recuperan después de 1814, como ha estudiado María Rodríguez Gutiérrez, pero resulta evidente que han desaparecido las tragedias del poder injusto.

Por detrás de Calderón se sitúa Comella con 18 obras y 99 representaciones, le siguen las 15 de Lope —al que volveré después-, con 130 representaciones; y por detrás de este se sitúan Moreto con 12 obras y 99 representaciones (incluidas las que escribe en colaboración con Matos Fragoso como El príncipe prodigioso y defensor de la fe), al que siguen Zavala y Zamora con 14 obras, Rodríguez de Arellano y Enciso Castrillón, ambos con 13 obras, y Cañizares con 11 obras y 82 representaciones. Otros autores como Belmonte Bermúdez, solo ven una obra representada, en este caso El diablo predicador y mayor contrario amigo, que sin embargo sube a las tablas en trece ocasiones antes y después de la Guerra. Lo mismo le ocurre a Guillén de Castro con sus Mocedades del Cid, que lo hace catorce veces, El delincuente honrado, de Jovellanos, en nueve, El Duque de Viseo de Quintana, también con el título de El espectro del castillo o Duque de Viseo ${ }^{26}$, con quince representaciones, y El sí de las niñas, con 16.

En cuanto a Lope de Vega, el repertorio que sube a las tablas lo componen quince títulos:

Las bizarrías de Belisa (4);

Lo cierto por lo dudoso o sea la mujer firme (18) —el 07 de enero de 1806 se indica que es refundición de Trigueros;

Las cuentas del Gran Capitán (8);

La esclava de su galán (5);

El mejor alcalde, el Rey (14);

Los milagros del desprecio (4);

La moza de cántaro (14) —el 19 de enero de 1806 se indica que es arreglo de Trigueros;

Obras son amores no buenas razones (7)

El perro del hortelano (12)

Sancho Ortiz de las Roelas: (23);

Si no vieran las mujeres (1);

${ }^{26}$ Así se anuncia los días 13 y 14 de abril de 1803. 
Los Tellos de Meneses (7);

De donde tienen origen los Monteros de Espinosa (9);

El ejemplo mayor de las desdichas o capitán Belisario (1).

Por el puente Juana (3), refundida por Trigueros.

Atribuida a Lope y en refundición de Trigueros se representó también Antes que te cases mira lo que haces, o Examen de maridos (6) ${ }^{27}$.

Otras obras y autores de éxito ${ }^{28}$ son Moreto, con Rey valiente justiciero, y el rico-hombre de Alcalá (12), El desdén con el desdén (16) y No puede ser el guardar una mujer (17); del mismo y Matos Fragoso, El príncipe prodigioso y defensor de la fe (17) Antonio de Zamora triunfa con El hechizado por fuerza (20) y Belmonte Bermúdez, Moreto y Martínez de Meneses, con Príncipe perseguido y tirano de Moscovia (14); mientras Antonio Coello, lo hace con Dar la vida por su dama [o conde de Sex] (12) y Hoz y Mota con El castigo de la miseria (11). Cierto éxito obtienen Cuando no se aguarda o príncipe tonto (8), de Ramírez de Arellano; Los amantes de Teruel (7), de Pérez de Montalbán; Del rey abajo ninguno o García de Castañar (8), de Rojas Zorrilla; Luis Vélez de Guevara con Reinar después de morir o sea Doña Inés de Castro (8); Villaviciosa con Cuantas veo tantas quiero (6); Antonio de Zamora con Quitar de España con honra el feudo de cien doncellas (6); y Fernando de Zárate con Vida y muerte del Cid Campeador y noble Martín Peláez (8).

Entre las obras de José de Cañizares, las más exitosas son El honor da entendimiento y el más bobo sabe más (14); El picarillo en España (13); Si una vez llega a querer, la más firme es la mujer (12) y El dómine Lucas (11).

En cierto modo, como han estudiado Varey ${ }^{29}$, la elección de algunas de estas obras viene dada por el modo en que las compañías escogen su repertorio y el éxito de que gozaron en siglos anteriores. Recurrir a determinadas «comedias viejas» era algo obligado para asegurar la acogida favorable cuando tenían que introducir los cambios en el cartel, impuestos por los contratos en determinados días de la semana o con ocasión de alguna festividad. No tengo espacio para analizar todo esto, pero sí diré que algunas de estas obras coinciden con las que estos autores destacan como de apertura y cierre de temporada, o en determinadas

\footnotetext{
${ }^{27}$ Atribuida erróneamente en el aviso a Lope de Vega es de Ruiz de Alarcón. Ver Peña, 2004.

${ }^{28}$ Por razones de espacio no puedo ofrecer más detalles, que quedarán para otra publicación.

${ }^{29}$ Varey, 1992, pp. 59-72.
} 
fechas como Navidad, carnaval o Corpus. Es lo que ocurre con Afectos de odio y amor, La banda y la flor, Cada uno para sí, No siempre lo peor es cierto y, con más favorable acogida, Las armas de la hermosura y Para vencer amor quever vencerle, de Calderón, elegidas para inaugurar la primera o la segunda temporada del año dramático en los años de 1708 a 1718, así como El desdén con el desdén y, entre las comedias nuevas, El picarillo en España, El honor da entendimiento, de Cañizares; en carnaval El diablo son los alcahuetes y el espíritu foleto y El hechizado por fuerza, que en Cádiz se representaba en cualquier época del año, así como la comedia de figurón El castigo de la miseria de Hoz y Mota; en Corpus, se representaban El dómine Lucas y Si una vez llega a querer, la más firme es la mujer, de Cañizares, y El origen de los Montero de Espinosa, de autor desconocido.

Creo que, para valorar el verdadero peso de la obra de Calderón, conviene apuntar que el autor más representado es Lope en 129 ocasiones, seguido de Rodríguez de Arellano, en 107; pero si incluimos en el cómputo la comedia El monstruo de la fortuna, la lavandera de Nápoles, escrita en colaboración con Rojas Zorrilla y Pérez de Motalbán, entonces le aventaja Calderón, al pasar a las 112 representaciones.

Mientras, de un autor tan popular por estos años como Comella suben a las tablas 18 obras con un total de 99 representaciones. En todo caso, en su conjunto el repertorio moderno suma 89 títulos y 629 representaciones.A ello cabría añadir la fuerte presencia del teatro musical, óperas y operetas que predominan en algunos meses del año.

En fin, para tratar de alcanzar a conocer lo que más le gusta al público, he examinado aquellas obras que se representan más de una decena de veces, aunque cabe decir que ya es raro que alguna lo haga más de una docena y que, por otra parte, no es frecuente que una obra se represente más de un día seguido. Lo que sí es seguro es que las obras que más le atraen tienen como tema el amor y el honor, bien sea tratado de forma seria, caso de Amar después de la muerte (11), o preferiblemente cómica, enredado con el tema de los celos y los engaños amorosos, caso de La dama duende (11), Casa con dos puertas (12), Para vencer amor querer vencerle (16), Lo cierto por lo dudoso o sea la mujer firme (18), alguna vez con indicación de ser refundición de Trigueros, y El perro del hortelano (12). Esto es así referido a las obras de Calderón y Lope como al resto del repertorio antiguo y moderno, dígalo si no El desdén con el desdén (16), No puede ser el guardar una mujer (17), alguna vez anunciada como "comedia antigua», o Si una vez llega a querer, la más firme es la mujer (12). 
No obstante, la que mejor alcanzó la fórmula del éxito es Sancho Ortiz de las Roelas (23), que tantos problemas morales presentó a la crítica neoclásica.

Precisamente el tema histórico es otro de los alicientes para acudir al teatro, como muestran las 14 representaciones de Príncipe perseguido $y$ tirano de Moscovia de Belmonte, Moreto y Martínez de Meneses; también en el repertorio moderno, donde triunfa El Católico Recaredo (11) de Valladares. Tampoco es extraño que tengan éxito notable las obras que tratan sobre los rigores del poder, como El mejor alcalde, el Rey (14) y Rey valiente justiciero y el rico-hombre de Alcalá (12). Particularmente es lógico, dada la coyuntura bélica que viven España y Cádiz, el triunfo de tragedias historiales que tratan sobre el poder injusto, desencadenante de una transgresión violenta y de una venganza que provoca el asedio, ataque y hostigamiento de una ciudad y sus habitantes, caso de Amar después de la muerte o el Tuzaní de las Alpujarras y Las armas de la hermosura, de Calderón.

De gusto aún más popular son las comedias de figurón, entre las que cabe mencionar algunas reivindicadas por Luzán como Entre bobos anda el juego o sea don Lucas del Cigarral de Moreto y El castigo de la miseria de Hoz y Mota — para la que su condición de "comedia de figurón» es el reclamo fundamental del anuncio en prensa- ${ }^{30}$ (11), Cuando no se aguarda o príncipe tonto (8), de Leiva Ramírez de Arellano. Notable éxito tienen Para averiguar verdades, el tiempo el mejor testigo (14), de Moncín, El dómine Lucas, una de las más conocidas de Cañizares, cuyo protagonista ha pasado a ser la encarnación del estudiante torpe, supersticioso y muy pagado de su hidalguía y El honor da entendimiento y el más bobo sabe más (14) del mismo autor; sin embargo, no hacen sombra a El hechizado por fuerza de Antonio Zamora (19).

No obstante, no triunfan las comedias de magia, a excepción de El diablo predicador y mayor contrario amigo de Belmonte Bermúdez, que se representa más de una docena de veces y El diablo son los alcahuetes y el espíritu foleto de Antonio Zamora, que solo se representa una vez, quizás porque las comedias de magia tienen mejor acogida en el teatro de sombras y fantasmagorías.

Dentro del repertorio moderno, sí se da el caso de que algunas obras se mantengan varios días seguidos en cartel, como Los efectos del juego,

\footnotetext{
${ }^{30}$ Así ocurre, por ejemplo, durante el carnaval del 10 de febrero de 1807.Ver Diario mercantil de Cádiz.
} 
de Enciso Castrillón, aunque luego no vuelva a representarse; aun así las obras que obtienen mejor acogida son traducciones que habían triunfado en Madrid como Los exteriores engañosos (14); igualmente destacan comedias sentimentales como El Duque de Pentiebre (21), de Ramírez de Arellano o tragedias como Blanca y Montcasin o sea los venecianos (19), puesta en verso por Teodoro de la Calle, y alguna refundición como $\mathrm{La}$ casualidad contra el cuidado (9) de Enciso Castrillón a partir de Coello.

Por último, en cuanto al teatro musical, su peso es significativo, pues se ofrecen unas 160 representaciones entre óperas y operetas, generalmente combinadas con sainetes, y otra piezas en un acto; a estas cabe añadir los oratorios, además de los consabidos tonadillas y bailes, junto a obras del Siglo de Oro a las que se ha añadido un importante componente musical, como en El mayor monstruo los celos y Tetrarca de Jerusalén.

Precisamente la música es uno de los elementos que puede coadyuvar al éxito de las obras lo mismo que la puesta en escena y la iluminación o la presencia de determinados actores que sirven de reclamo en los avisos, como Nicolás Muñoz en el papel de figurón en Entre el amor y el honor, el honor es lo primero, los días 24 a 26 de mayo de 1806, o el de la primera dama Agustina Torres en Obras son amores no buenas razones el 24 de septiembre de 1809, entre otras ocasiones.

En todo caso, creo haber puesto en cuestión que Calderón y otros autores del Siglo de Oro fueran escasamente representados, pues el cotejo resulta bastante equilibrado entre los 104 títulos y 648 representaciones de estos, frente a los 89 títulos y 629 representaciones del repertorio moderno, aunque no cabe duda de que el interés por el Siglo de Oro pueda tener que ver no solo con el del público, sino también con la economía de las compañías y el esfuerzo que suponía hacerse con un repertorio nuevo. 


\section{Bibliografía}

Bigelow, Gary E., «De un castigo, tres venganzas y la coincidencia de justicia y venganza en el teatro de Calderón», en Actas del Congreso Internacional sobre Calderón y el teatro español del Siglo de Oro, vol. I, Anejos de la Revista Segismundo, 6, 1983, pp. 827-838.

Caldera, Ermanno, "Calderón desfigurado (sobre las representaciones calderonianas en la época prerromántica)", Anales de Literatura Española, 2, 1983, pp. 57-81.

Cantos Casenave, Marieta, «El discurso de Frasquita Larrea y la politización del Romanticismo», Cuadernos de Ilustración y Romanticismo, 10, 2002, pp. 3-13.

Cantos Casenave, Marieta, «La conjura de Orfeo. Música en tiempos de guerra (1808-1814)", España contemporánea: Revista de Literatura y Cultura, tomo 21, 2, monográfico «La guerra y la paz. 1808-1939», 2010, pp. 67-80.

Cantos Casenave, Marieta, «Acerca de la literatura patriótica de María Manuela López de Ulloa», en Hacia 1812 desde el siglo ilustrado, coord. Fernando Durán López, Gijón, TREA, 2013, pp. 821-833.

CARnero, Guillermo, "Calderón y cierra España», Románticos y liberales, 1982, pp. 34-39.

Cotarelo y Mori, Emilio, Isidoro Máiquez y el teatro de su tiempo, Madrid, Imprenta de José Perales Martínez, 1902.

Fernández Cabezón, Rosalía, «El teatro político de Félix Enciso Castrillón», en Lecturas del pensamiento filosófico, estético y político. Actas XIII Encuentro de la Ilustración al Romanticismo (1750-1850), ed. María del Carmen García Tejera, Cádiz, Universidad de Cádiz, 2008, pp. 53-68.

Freire López, Ana María, El teatro español entre la Ilustración y el Romanticismo: Madrid durante la guerra de la independencia, Madrid / Frankfurt, Iberoamericana / Vervuert, Madrid, 2009.

Johnston, Robert M., «El movimiento escénico y las "relaciones proxémicas” en $A$ secreto agravio, secreta venganza y El pintor de su deshonra de Calderón", Texto e imagen en Calderón: XI Coloquio Anglogermano sobre Calderón, ed. Manfred Tietz, Stuttgart, Franz Steiner Verlag, 1998, pp. 235-249.

Larraz, Enmanuel, "Teatro y política en el Cádiz de las Cortes», en Actas del $V$ Congreso Internacional de Hispanistas, 1977. Disponible en: < http://www. cervantesvirtual.com/nd/ark:/59851/bmc4j2g0> [16/01/2017].

Lloréns, Vicente, El Romanticismo español, Castalia, Madrid, 1989.

Mackenzie, Ann L., La escuela de Calderón estudio e investigación, Hispanic Studies TRAC (Textual Research and Criticism), vol. 3, Liverpool, Liverpool University Press, 1993. 
MCKendrick, Melveena, «La imagen pintada en Darlo todo y no dar nada», en Texto e imagen en Calderón: undécimo Coloquio Anglogermano sobre Calderón, ed. Manfred Tietz, Stuttgart, Franz Steiner Verlag, 1998, pp. 158-170.

Novo, Yolanda, "Tragedia y tragicidad en algunas comedias de la Parte IX (1691), en Calderón 2000. Homenaje a Kurt Reichemberger en su ochenta cumpleaños, ed. Ignacio Arellano, Madrid, Reichenberger, 2002, vol. I, tomo II, pp. 283-294.

PeÑA, Margarita, «Juan Ruiz de Alarcón: biografía y comedias», en Paraninfos, segundones y epígonos de la comedia del Siglo de Oro, coord. Ignacio Arellano, Barcelona, Anthropos, 2004, pp. 61-68.

Ramos Santana, Alberto, «La vida cotidiana en el Cádiz de las Cortes. El recurso a la prensa como fuente para su estudio», en La guerra de pluma. Estudios sobre la prensa de Cádiz en el tiempo de las Cortes (1810-1814), Cádiz, Universidad de Cádiz, 2008, vol. III, pp. 21-101.

Rodríguez Gutiérrez, María, «Agustina Torres, la actriz patriota del teatro de Cádiz durante la Guerra de la Independencia y las Cortes», en 1808-1812. Los emblemas de la libertad, ed. Alberto Ramos Santana y Alberto Romero Ferrer, Cádiz, Universidad de Cádiz, 2009, pp. 507-524.

Romero Ferrer, Alberto, «Lecturas de Calderón de la Barca: siglos XVIII, Xix y XX», Cuadernos de Ilustración y Romanticismo, 19, 2013, pp. 501-505.

Romero Peña, María Mercedes, El teatro en Madrid durante la guerra de la independencia, 1808-1814, Madrid, Fundación Universitaria Española, 2006.

Romero PeÑa, María Mercedes, «La escena madrileña de 1800 a 1808», Cuadernos para Investigación de la Literatura Hispánica, 33, 2008, pp. 185-224.

SAura, Alfonso, "Teatro francés traducido en el Madrid de 1808», Anales de Filología Francesa, 16, 2008, pp. 205-221.

VArey, John E., Los libros de cuentas de los corrales de comedias de Madrid: 17061719. Estudio y documentos, London, Tamesis, 1992. 